\title{
Mitaka "Taiyokei" (solar system) walk; a collaborative science outreach program by institues, local government, and shopping stores
}

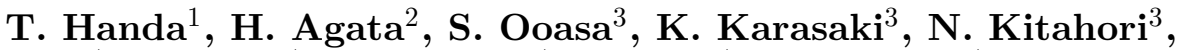

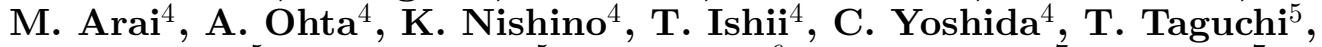
E. Totsuka ${ }^{5}$, S. Watanabe ${ }^{5}$, H. Fukaya ${ }^{6}$, Y. Kakihana ${ }^{7}$, A Inoue ${ }^{7}$,

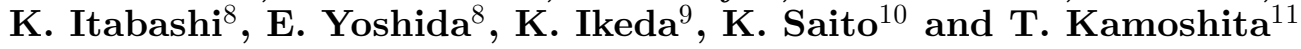

${ }^{1}$ Depart. Astron. \& Phys., Kagoshima Univ., Korimoto 1-21-35, Kagoshima 890-0065, Japan email: handa@sci.kagoshima-u.ac.jp

${ }^{2}$ National Astronomical Observatory of Japan, ${ }^{3}$ Mitaka Network University Organization

${ }^{4}$ Mitaka society of commerce and industry, ${ }^{5}$ Mitaka-city tourism association

${ }^{6}$ Ghibli museum Mitaka, ${ }^{7}$ Mitaka Municipal Office, ${ }^{8}$ Mitaka Town Management Organization

${ }^{9}$ Mitaka international society for hospitality, ${ }^{10}$ Mitaka city arts foundation

${ }^{11}$ NPO Flowers and Green City Mitaka Creative Association, ${ }^{12}$ MT-planning Co. Ltd.

It is difficult to get a real scale image of the solar system through lecture. A scale model is a classical and one of good solutions (e.g. Handa et al. 2003, Handa et al. 2008). Through this model, people living in or visiting to the city can physically understand the scale of the solar system. This scale gives $1 \mathrm{~cm}$ for Earth's diameter and $115 \mathrm{~m}$ for 1 AU. However, some gadget is required to make it attractive for public citizens.

We have, therefore, started a program "Mitaka TAIYOKEI walk" since 2009. In this program we made a scale model of the solar system with 1:1,300,000,000 over Mitaka city, Tokyo and link it to many spots in the city. More than 100 shopping stores and facilities in and around Mitaka city join this program every year. We set the Sun at the railway station and put a pictorial flag of the Sun in the same scale. The city area is divided into 11 annual zones centered on the "Sun" and each zone is assigned to a planet, the Sun, Ceres, or Pluto. Each shop to entries has a pictorial flag and a stamp of the planet of the zone. At several spots in the city, a visitor can get a booklet. It shows a figure of sizes of all planets in the same scale, and astronomical data of the planets, the concept of the program, and a map of the shops. A person who collects the stamps with some criteria can get some novelties with prizes after famous astronomers. During the program several science-café talks on astronomy were also held. Through this program shop keepers, public servants, residents, and visitors are stimulated the interest to astronomy. The program can become a tourist attraction and is a good outreach with the widest entrance. We will continue the program for many years.

The official web page is http://www.taiyokei-walk.jp/. Please visit there.

\section{References}

Handa T., Matsuura K., \& Koike K. 2003, in: A. -L. Melchior \& R. Ferlet (eds.) Global Hands-on Universe 2002, (Frontier Group, ESA), ISBN 2914601107, p. 221

Handa T., Matsuura K., \& Koike K. 2008, in: T. Handa \& M. Okyudo (eds. ) Global Hands-on Universe 2007, Frontiers Science Serise 54, (Tokyo: Univsersal Academy Press), ISBN9784-904164-05-1, p. 209 